\title{
Experimental investigation of bio-enhancer drilling fluid additive: Can palm tree leaves be utilized as a supportive eco-friendly additive in water-based drilling fluid system?
}

\author{
Abo Taleb T. Al-Hameedi ${ }^{1} \cdot$ Husam H. Alkinani ${ }^{1} \cdot$ Shari Dunn-Norman ${ }^{1} \cdot$ Mustafa A. Al-Alwani ${ }^{1}$ \\ Waleed H. Al-Bazzaz ${ }^{2}$. Abdullah F. Alshammari ${ }^{1} \cdot$ Hussien W. Albazzaz ${ }^{1} \cdot$ Rusul A. Mutar ${ }^{3}$
}

Received: 9 May 2019 / Accepted: 18 August 2019 / Published online: 24 August 2019

(C) The Author(s) 2019

\begin{abstract}
Serious problems will be presented due to using conventional chemical additives to regulate the drilling mud properties, as they have health, safety, and environmental side effects. Thus, there is a considerable necessity for alternative multifunctional bio-enhancer drilling mud additives, which can assist in optimizing the drilling fluid specifications and enhance its effectiveness with the least effects on the environment and the drilling personnel safety. The effects of adding two concentrations of palm tree leaves powder (PTLP) to water-based mud were conducted under fresh and aged conditions using standard API drilling fluids testing methods such as rheometer/viscometer, $\mathrm{pH}$ meter and temperature, and filter press. All tests results were minutely recorded to understand the influence of PTLP additives on the drilling mud properties. The results indicated that PTLP as an effective material to be used as $\mathrm{pH}$ reducer, viscosity reducer, and as an excellent filtration loss control agent under the surface and sub-surface conditions. Thus, PTLP has excellent feasibility to be utilized as biodegradable drilling mud additive replacing or at least supporting other conventional chemical additives, which have usually been used for the same purposes such as lignosulphonate, chrome-lignite, and Resinex. Finally, this work can serve as a practical guide for minimizing the cost of the drilling fluid and reducing the amount of non-biodegradable waste disposed to the environment.
\end{abstract}

Keywords Palm tree leave powder $\cdot$ Bio-enhancer $\cdot$ Drilling fluid $\cdot$ Aged conditions

\section{Introduction}

Drilling fluid is very important in the drilling operation. If the drilling fluid was not designed properly, many unwanted consequences can happen such as lost circulation and stuck pipe issues (Alkinani et al. 2019; Al-Hameedi et al. 2018). To obtain the desired properties, chemical and non-biodegradable materials have been the traditional additives that are used in drilling fluids. With the increase in the environmental concerns regarding traditional chemical additives,

Abo Taleb T. Al-Hameedi

ata2q3@mst.edu

Husam H. Alkinani

hhappf@mst.edu

1 Missouri University of Science and Technology, Rolla, MO, USA

2 Kuwait Institute for Scientific Research, Kuwait City, Kuwait

3 Ministry of Communications and Technology, Baghdad, Iraq the oil and gas industry has been focused on driving drilling fluid additives into a safer and environmentally friendly process. Drilling fluid consists of the base fluid and solid materials that perform a specific type of function to obtain good results. Drilling fluids must be chosen carefully to avoid any drilling problems and ensure good drilling performance. The factors that guide the selection of mud additives and drilling fluids are complicated and inter-related (Okorie 2009).

Nowadays, drilling practices encourage the use of conventional water-based drilling fluid over the common practice of oil-based muds for environmental and safety reasons. The increased focus of using toxic chemical additives in drilling fluids for economic performance allowed little attention to be focused on the environment, health, and safety issues. These common chemical additives including potassium chloride, potassium sulfate, polyamine, chromium-containing thinners, fluid loss additives, etc., have an overall negative environmental impact and are expensive (Amanullah 2007).

Currently, the US environmental protection agency (EPA) has issued strict guidelines on the discharge of water to the 
sea and the disposal of drilling cuttings. These guidelines have motivated researchers to develop new biodegradable additives that are cost-effective and environmentally friendly to deliver optimum drilling performance. Recent research has been conducted on the use of biodegradable waste materials as drilling fluid additives to prevent environmental risks and ensure success (Amadi et al. 2018).

Okon et al. (2014) examined the use of rice husk as an environmentally friendly filtration control additive. Their results showed that $20 \mathrm{ppb}$ concentration of rice husk was able to reduce fluid loss by $65 \%$ when comparing it to $10 \mathrm{ppb}$ concentration of carboxymethyl cellulose (CMC). However, the rice husk may have good results in fluid loss control, but it may have undesirable results regarding plastic viscosity. Iheagwara (2015) in his research showed that the banana peel exhibits similar properties when comparing it to caustic soda. Similarly, Adebowale and Raji (2015) examined the use of banana peel ash as a substitute additive for $\mathrm{NaOH}$ to enhance $\mathrm{pH}$ properties for drilling fluids and control corrosion. The banana peel ash proved to achieve good results for $\mathrm{pH}$.

Irawan et al. (2009) studied the use of corncob and sugarcane as a viscosifying agent. The results from their studies showed good improvements in plastic viscosity but resulted in a decrease in yield point and gel strength. These results negatively had an impact on gel strength and yield point. Nmeghu et al. (2014) examined the effect of using cellulose from corncob in improving the rheological properties of water-based muds. Their results showed that the corncob reduces fluid loss and is effective when comparing it to polyanionic cellulose (PAC). The suitability of cashew and mango leaves extract in improving rheological properties was examined by Omotioma et al. (2014). Their results showed that the leaves extract improved the rheological properties of mud. Nyeche et al. (2015) studied the use of potato starch in enhancing mud rheological properties. Their results showed that rheological and filtration properties were impacted negatively.

Much other non-toxic waste material that can be exploited to be recycled and be put to good use for the oil industry, including but not limited to palm tree leaves (PTL), which is mostly located in areas of tropical climate or desert regions. Most palm trees produce dates, which are widely consumed in the Middle East and North Africa. An investigation on the availability of palm tree leaves was carried out. There are roughly around 120 million date palm trees in the world, and the Arab world itself has more than 84 million date trees (Amanullah et al. 2007). The majority of which are present in countries such as Saudi Arabia, Iraq, Northern Africa, Pakistan, India, and the US state of California. Date palm trees leave a huge amount of wastes such as dry leaves, and these wastes can create a severe problem with farming industries. Usually, these wastes are burned in farms or disposed in landfills that can cause environmental pollution (Zafar 2016).

In this work, the interaction of biodegradable palm tree leaves powder (PTLP) and water-based mud was investigated under the fresh and aged conditions, for the potential use of this environmentally friendly additive (PTLP) to enhance the physical characteristics of the drilling fluid such as the rheological properties and filtration specifications. In addition, PTLP is being examined as an alternative for some of the conventional drilling fluids such as traditional thinners chemicals to guarantee safety, control any environmental concerns, minimize the drilling cost, and improve drilling fluid properties.

\section{Temperature effects on drilling fluids and the importance of aged conditions}

One of the most complicated issues in regards to drilling fluids is the range of operational temperatures for their components during drilling operations. The temperature is proportionally related to the depth. In different words, the temperature at the bottom of the hole increases as the well deepens in the formation; therefore, it is crucial to secure the rheological properties as well as filtration properties of the drilling fluid. These properties of the mud are heavily related to the temperature effects, and under downhole conditions the results may be significantly different from the ones measured at the surface, which in return lead to misinterpretations that can generate future undesirable wellbore consequences such as poor hole cleaning, mechanical stuck pipe, drag issues, wash pipe, mud clotting, and many more complex problems. Hence, when drilling fluids are exposed to relatively high temperatures, the portion of the fluid that is at the lower part of the wellbore becomes increasingly thick, and the situation aggravates even more under static conditions (pump off conditions) in which the prolonged heating may cause the drilling fluid to certain solidification process (Ali and Al-Marhoun 1990; Basra Oil Company 2011).

The influence of temperature on drilling mud can be caused by very complex factors, some of which are more dominant than others. Factors that come into mind are including but not limited to, reduction in the degree of hydration of the bentonite as well as polymers, reduction in the viscosity of the lifting and suspending medium, decreasing alkalinity, increasing dispersion of clay particles, and an increase in the degradation rate of additives. As a result, all these processes take place in the drilling fluid simultaneously as the temperature is varied, an interpretation of the observed results will only be possible in cases whereby some of the effects are predominant and as such be easily identified (Basra Oil Company 2011). 
One of the more important effects due to high temperatures is the detrimental effect on drilling fluid rheology, which can accumulate and build up all the cuttings and affect the hydraulic capabilities as well as encounter some degree of flocculation in the drilling mud. Because of this latter case, bad quality-filter cake can be resulted, which is thick enough to increase the potential of the mechanical stuck pipe due to the formation of a larger contact area between the drill string and the filter cake (Basra Oil Company 2008).

On the other hand, if poor permeability is presented, the condition of the filter cake will increase the filtrate into the formation. Thermal degradation of filtrate control-additives and viscosifiers aggravates the problem previously described. For instance, at temperatures around $300^{\circ} \mathrm{F}$, starch in the drilling fluid begin to experience a process known as hydrolysis and depolymerization of thinners or irreversible chemical reactions, leading to a complete degradation of the drilling mud (Chesser and Enright 2013; Basra Oil Company 2011).

In brief, the temperature has to be treated as one important contaminate in drilling fluids. It is a difficult procedure to handle such condition; however, its detrimental effect on bentonite, polymer hydration, clay flocculation, rheological problems, and filtration characteristics as described above is some strong evidence that supports this claim. The most unique part of all this is that temperature itself has no treatment and is uncontrollable. The only solution to this problem is the design of the drilling fluids and the chemical additives that are used in the operations, and these chemical materials have to be added to the mud slurry in surface tanks as a preventive approach for adapting the effects of the temperature.

"Drilling fluid aging is the process in which a drilling fluid sample, previously subjected to a period of shear, is allowed to more fully develop its rheological and filtration properties. The time period needed to more fully develop properties varies from as little as several hours (usually $16 \mathrm{~h}$ and moderate temperature aging up to $122^{\circ} \mathrm{F}\left(50^{\circ} \mathrm{C}\right)$ ) to as much as several days. The aging can be done at either ambient or elevated temperatures. Aging is done under conditions which vary from static to dynamic and from ambient to highly elevated temperatures' (Fann Instrument Company 2005).

The samples of drilling mud have the potential to be mixed at ambient temperatures in an abundance of open containers that are mostly made from metal, plastic or glass materials. There is little or no incompatibility that exists between normal water-based mud and these materials under ambient temperature conditions. Hence, the drilling fluid sample is typically put in this aged cell to reflect the wellbore container under sub-surface conditions environment as shown in Fig. 1 (Fann Instrument Company 2005).

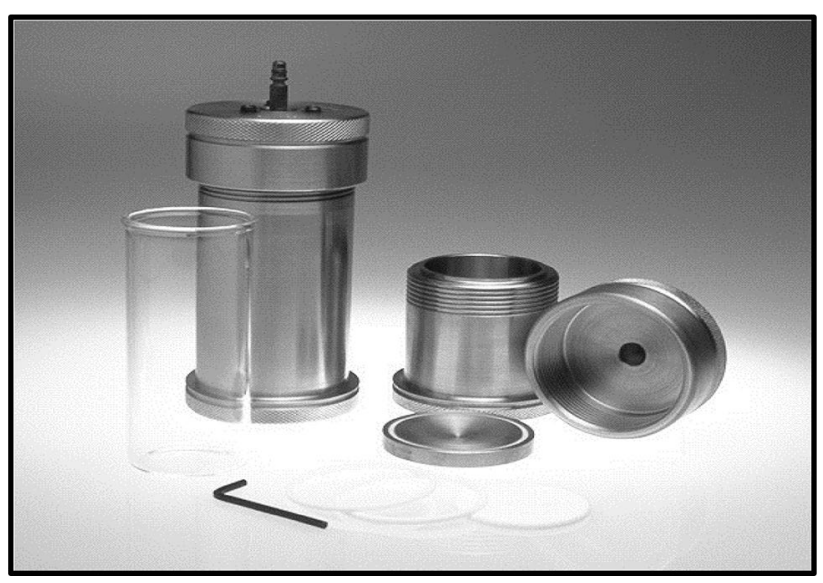

Fig. 1 Aged cell and accessories (Fann Instrument Company 2005)

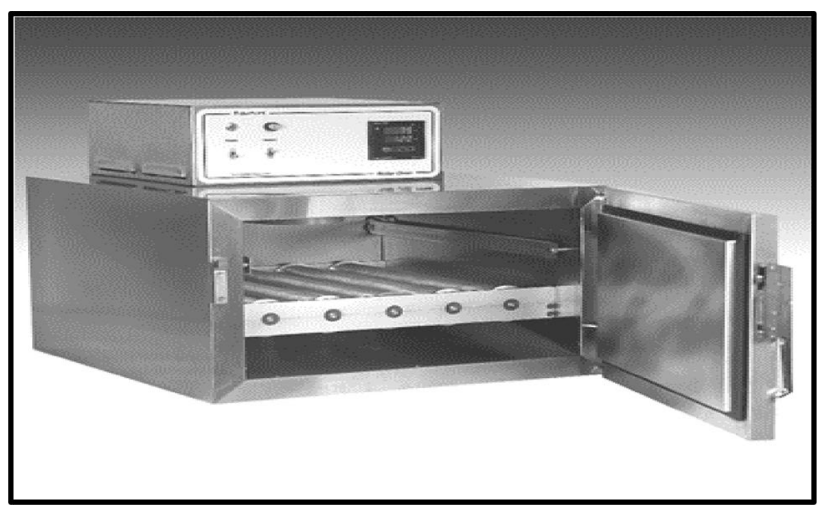

Fig. 2 Roller oven and accessories (Fann Instrument Company 2005)

Most drilling fluids contain a base liquid such as water and additives which must be dissolved or mechanically altered into the liquid to form a homogenous fluid. The resulting fluid from the drilling process may contain one or more of the following: water-dispersible (soluble) polymers or resins, clays or other insoluble but dispersible fine solids, and soluble salts. Then, the fluids undergo an experimental procedure where it is mixed or sheared for appropriate times to achieve a homogenous mixture, once that is figured out then the fluids are set aside to "age." The aging process is performed under conditions which vary from static to dynamic and from ambient to highly elevated temperatures using roller oven as shown in Fig. 2 (Fann Instrument Company 2005).

Due to high influential consequences of the temperatures and to guarantee successful drilling operations to be accomplished, the chemical materials have to be continuously monitored and tested under the aged conditions when implementing a pilot test. Plainly, surface conditions' measurements do not reflect the actual stability of the drilling fluid properties, and they do not represent bottom-hole conditions. 
In different words, because of elevated temperatures and aging times at the sub-surface, the drilling fluid characteristics will be changed and as a result, serious problems may be caused downhole (Basra Oil Company 2007). Therefore, aged conditions have been carried out for the two concentrations samples of PTLP by placing them in the oven under $55^{\circ} \mathrm{C}\left(130^{\circ} \mathrm{F}\right)$ for $24 \mathrm{~h}$, in order to compare the results of the surface and aged conditions and to ensure the effectiveness of PTLP additives as explained and shown in detail in the results and discussion sections.

\section{Experimental procedure and results}

To distinguish the effect of presenting various concentrations of PTLP on the physical properties of the drilling fluid, the reference fluid (RF) was originally prepared, and it consisted of $700 \mathrm{cc}$ of water, $1 \mathrm{~g}$ of $\mathrm{NaOH}$, and $45 \mathrm{~g}$ of bentonite. Then, full-set measurements were conducted and recorded to the reference fluid in order to be compared to the results of adding two concentrations of PTLP. Then, 1.5\% $(11 \mathrm{~g})$ and $3 \%(22 \mathrm{~g})$ concentrations of PTLP were added to the reference fluid. Afterword, full-set measurements have been conducted to investigate the effect of PTLP additives on the physical properties of the reference fluid.

$1.5 \%(11 \mathrm{~g})$ and $3 \%(22 \mathrm{~g})$ concentrations of PTLP were first evaluated at the fresh conditions, and then the same concentrations of PTLP were conducted at the aged conditions to distinguish the bacteria issues and the temperature impact, by leaving the samples of PTLP in the static conditions (laboratory room) for $24 \mathrm{~h}$, then placing them in the oven (dynamic conditions) under $55^{\circ} \mathrm{C}\left(130^{\circ} \mathrm{F}\right)$ for another $24 \mathrm{~h}$. For the fresh and aged environments, several properties of drilling fluid were measured, including but not limited to, the rheological properties, the filtration characteristics, and the $\mathrm{pH}$. For instance, the rheological properties including the plastic viscosity, yield point, initial gel strength for $10 \mathrm{~s}$, and the final gel strength for $10 \mathrm{~min}$ were conducted using the rotary viscometer. The filtration characteristics including the fluid loss in cc/7.5 min and cc/30 min as well as the filter cake thickness were measured using the standard low-temperature and low-pressure (LTLP) API filter press at 100 psi.

Tables 1 and 2 show the variation of the results due to adding $1.5 \%$ and $3 \%$ concentrations of PTLP additives under the surface and sub-surface conditions, respectively.

\section{Discussion}

The discussion of the experimental results was broken into two sub-sections which are fresh and aged conditions. PTLP is a multifunctional bio-enhancer additive with a negligible
Table 1 The results of adding various concentrations of PTLP to the reference fluid (fresh conditions)

\begin{tabular}{llll}
\hline Property & RF & $1.5 \%$ PTLP & 3\% PTLP \\
\hline Plastic viscosity $(\mathrm{PV}),(\mathrm{cp})$ & 8 & 9 & 12 \\
Yield point $(\mathrm{YP}),\left(\mathrm{Ib} / 100 \mathrm{ft}^{2}\right)$ & 12 & 5 & 5 \\
Initial gel strength, $\left(\mathrm{Ib} / 100 \mathrm{ft}^{2}\right)$ & 15 & 6 & 7 \\
Final gel strength, $\left(\mathrm{Ib} / 100 \mathrm{ft}^{2}\right)$ & 20 & 11 & 12 \\
$\mathrm{pH}$ & 11 & 8.8 & 8 \\
7.5 min filtrate, $(\mathrm{cc})$ & 6 & 4 & 3.25 \\
30 min filtrate, $(\mathrm{cc})$ & 12.5 & 9.25 & 8.5 \\
Filter cake thickness, $(\mathrm{mm})$ & 3 & 1.9 & 2 \\
\hline
\end{tabular}

Table 2 The results of adding various concentrations of PTLP to the reference fluid (aged conditions)

\begin{tabular}{lll}
\hline Property & $1.5 \%$ PTLP & $3 \%$ PTLP \\
\hline Plastic viscosity $(\mathrm{PV}),(\mathrm{cp})$ & 9 & 9 \\
Yield point $(\mathrm{YP}),\left(\mathrm{Ib} / 100 \mathrm{ft}^{2}\right)$ & 6 & 5 \\
Initial gel strength, $\left(\mathrm{Ib} / 100 \mathrm{ft}^{2}\right)$ & 6 & 6 \\
Final gel strength, $\left(\mathrm{Ib} / 100 \mathrm{ft}^{2}\right)$ & 12 & 11 \\
$\mathrm{pH}$ & 8.7 & 8.1 \\
7.5 min filtrate, $(\mathrm{cc})$ & 4.25 & 4 \\
30 min filtrate, $(\mathrm{cc})$ & 9.5 & 9 \\
Filter cake thickness, $(\mathrm{mm})$ & 2 & 2 \\
\hline
\end{tabular}

increasing on PV, significant decreasing in YP and the gel strength, a tangible improvement of filtration properties, and a moderate effect on $\mathrm{pH}$ of water-based mud.

\section{Fresh conditions}

Starting with the rheological properties, PTLP had inconsistent results since it tremendously reduced YP and gel strength at both $1.5 \%$ and $3 \%$ concentrations. However, PV was negligibly increased at $1.5 \%$ of PTLP additive, while $\mathrm{PV}$ was tangibly maximized at $3 \%$ concentrations. The main reasons for this incompatible agreement in regard to the two viscosity components are the irregularity in the particle size distribution of PTLP, and the other reason is the simplicity of the food processor that was used to grind the palm tree leaves, which in return resulted in some coarse particles in PTLP. In different words, PV was majorly increased at $3 \%$ of PTLP additives due to high friction between the solids and liquid particles. Thus, using advanced and efficient grinder as well as doing sieve analysis will significantly assist to eliminate the discrepancy in these results. Figure 3 illustrates the effect of PTLP on the rheological properties.

When analyzing the effect of $1.5 \%$ and $3 \%$ of PTLP on the seepage loss, it can be clearly observed that PTLP resulted in reducing the volume fluid loss compared to the initial 


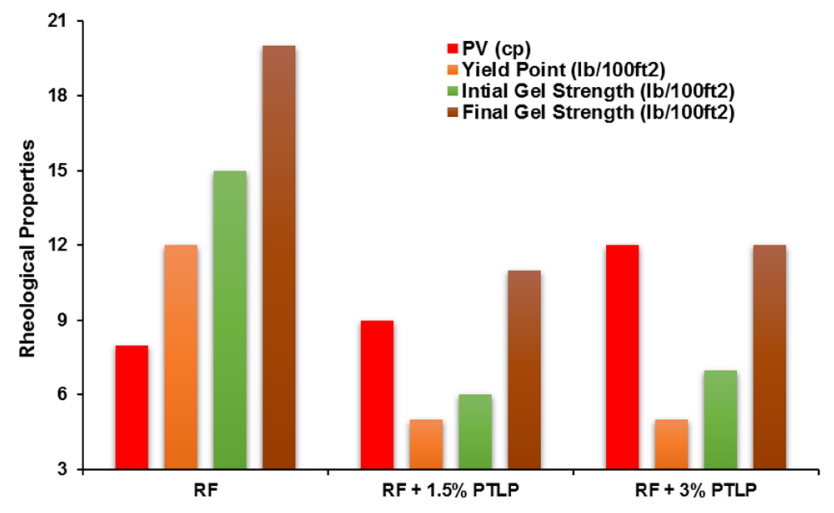

Fig. 3 The influence of PTLP on the rheological properties (fresh conditions)

reference fluid as shown in Fig. 4. Similarly, the results of the mud cake thickness of adding $1.5 \%$ and $3 \%$ of PTLP showed improvement by providing thin and impermeable mud cake, and that is seen in Fig. 4. Additionally, the two concentrations did not show a significant difference in the results regarding the rheological and filtration characteristics except for PV for the reason mentioned above. Thus, it is recommended to use low concentrations of PTLP between $1 \%$ as a minimum and $2 \%$ as a maximum in order to provide optimal performance.

To avoid the corrosion on the drilling equipment and to provide an excellent environment for the hydration and desperation between the clay and chemical additives, it is crucial to have the right $\mathrm{pH}$ in make-up water, and the typical range is from 9.5 to 11.5 (Basra Oil Company 2007). After adding PTLP with $1.5 \%$ and $3 \%$ concentrations, the measurements showed that PTLP moderately reduced $\mathrm{pH}$ as compared to the reference fluid as shown in Fig. 5, suggesting its capability to be used as $\mathrm{pH}$ reducer in water-based mud.

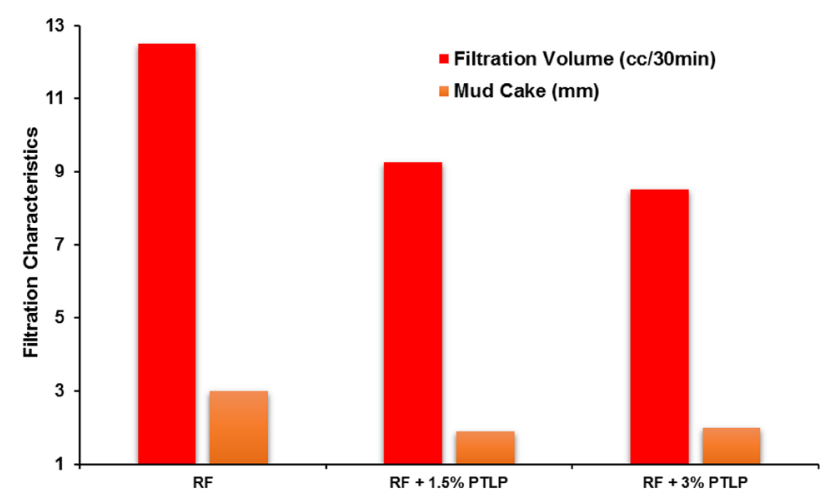

Fig. 4 The influence of PTLP on the filtration characteristics (fresh conditions)

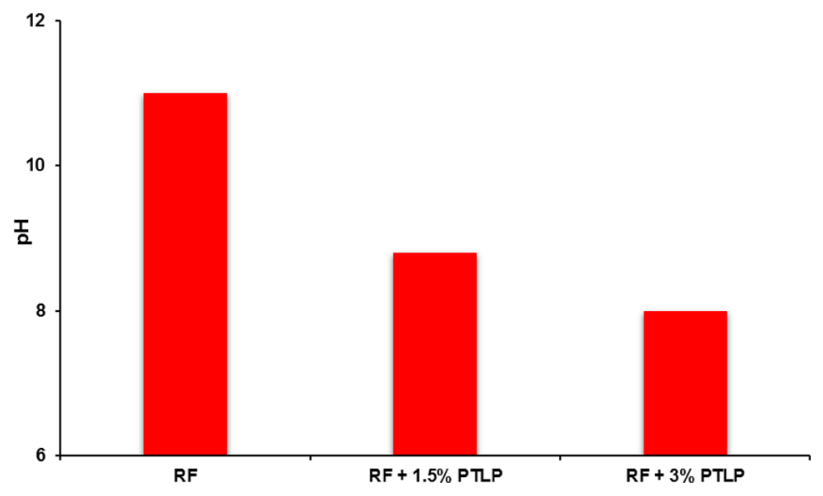

Fig. 5 The influence of PTLP on $\mathrm{pH}$ (fresh conditions)

\section{Aged conditions}

In regard to the second sub-section of this laboratory work, samples containing the same two concentrations of PTLP have been left for two days: the first day was under the static condition in the laboratory room to diagnose if there were bacteria issues or not, and the second day was under the roller oven conditions to understand the temperature effect. The results showed that the temperature and the roller oven conditions did not affect the reference fluid with PTLP additives. In addition, there were no bacteria problems with PTLP additives. As shown in Tables 1 and 2, both results of the fresh and aged conditions had almost the same performance on the reference fluid in regards to YP, filtration characteristics, and $\mathrm{pH}$.

However, PV was differently affected by PTLP at $3 \%$ concentration, where PV was tangibly affected by $3 \%$ concentration for the fresh conditions, while PV was negligibly influenced by $3 \%$ concentration for the aged conditions. The variation in PV results for the fresh and aged conditions using 3\% of PTLP can be due to an excellent homogeneity and a premium interaction between the continuous phase (water) and dispersed phase (bentonite) as well as due to leaving PTLP samples for $48 \mathrm{~h}$ which provided a sufficient time for the hydration. That as a result leads to reducing the friction forces in the reference fluid. Figures 6, 7, and 8 illustrate the impact of PTLP on the reference fluid (RF) properties under the aged conditions.

\section{Performance comparison of PTLP with other environmentally friendly food waste products}

With the need for biodegradable additives to be exploited as substitutional drilling mud materials because of their affordable price and being environmentally friendly, research on food waste products has developed. Food waste products

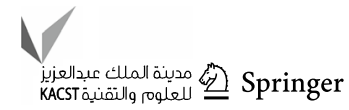




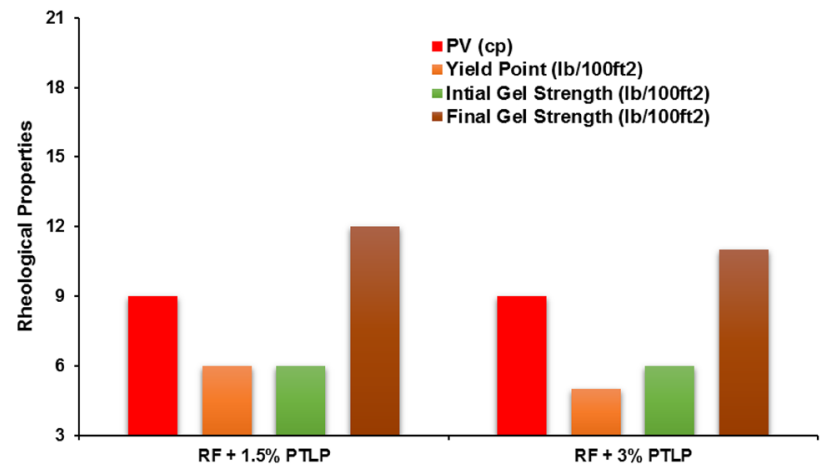

Fig. 6 The influence of PTLP on the rheological properties (aged conditions)

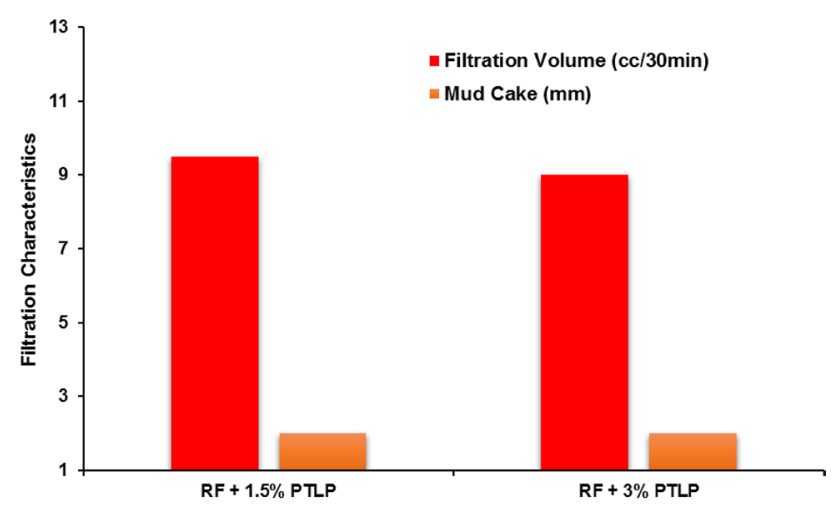

Fig. 7 The influence of PTLP on the filtration characteristics (aged conditions)

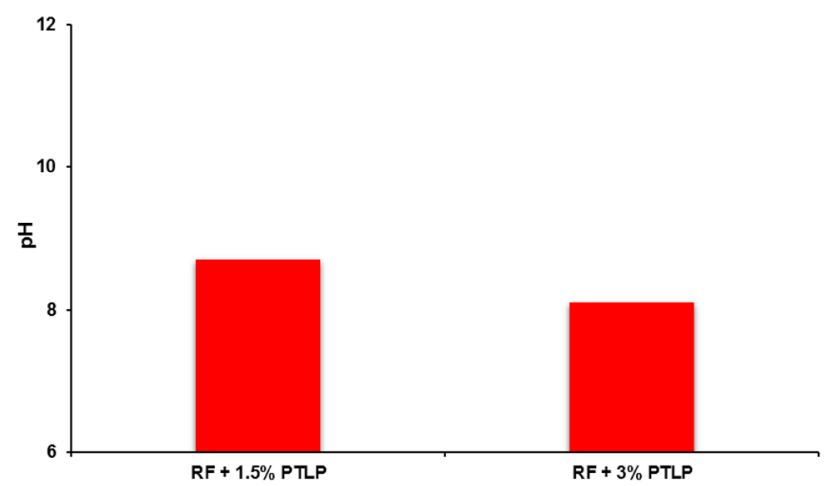

Fig. 8 The influence of PTLP on pH (aged conditions)

can be utilized as a supportive option for conventional nonbiodegradable and toxic materials as they can produce promising findings. The publicity of utilizing food waste products is fundamental because of their low cost and their friendly impact on the environment. Food waste is among the waste issues that are common and present throughout the world. Food waste is among the highest concerns regarding waste as it is generated daily around the globe. If not managed properly, it can pose severe threats to the environment and public health. Recycling food waste is a great option, and it can be utilized for drilling fluids. Some of the examinations that have been executed in regard to food waste products to experience their influences on drilling fluid characteristics are as summarized below in the subsequent paragraphs (AlHameedi et al. 2019a). The aim of this section is to compare the performance of PTLP to other environmentally friendly drilling fluid additives in the literature.

One of the food waste materials that have the potential to be used in the oil and gas industry is grass. Grass powder (GP) had the capability to be exploited as an environmentally friendly material to be utilized in drilling fluids. AlHameedi et al. (2019b) investigated GP as an origin of waste to execute laboratory experiments to regulate the filtrate and filter cake. The GP reduced the seepage loss and ameliorated the mud cake characteristics proving to be a competitive additive as compared with the common starch material. Potato peels powder (PPP) is another instance of food waste materials performed by Al-Hameedi et al. (2019c). They utilized the PPP to conduct laboratory measurements such as filtration and fluid rheological specifications. Their outcomes exhibited that the PPP had no effect on the drilling fluid density; however, it had an influence on the rheological properties by maximizing the plastic viscosity and minimizing the yield point and the gel strength. In addition, fluid loss was decreased, thus making it an efficient drilling mud additive.

In addition, Al-Hameedi et al. (2019d) performed an experimental study using mandarin peels powder (MPP) to improve filtration characteristics and mud rheology specifications. Based on their findings, the MPP enhanced mud rheological characteristics and reduced the seepage loss, suggesting the MPP ability to be exploited as an effective drilling fluid material. Moreover, in this laboratory investigation, PAC-LV was used to be compared with MPP in terms of enhancing the physical and chemical properties. The experimental findings revealed that MPP had the potential to be used as an environmentally friendly additive for the drilling fluid. In the same context, Al-Hameedi et al. (2019e) investigated the possibility of exploiting fibrous food waste material (FFWM) as an environmentally friendly drilling fluid additive. FFWM was collected and processed in-house. The investigational assessment was implemented to test the capability of FFWM to improve different specifications of water-based drilling fluid under two various $\mathrm{pH}$ conditions. The FFWM was first examined at $9.3 \mathrm{pH}$, and then the $\mathrm{pH}$ was maximized utilizing sodium hydroxide to 11.5 . The experimental findings showed that FFWM had a significant reinforcement in the rheology and filtration characteristics, proposing the feasibility of investing this material as a rheology elevator and seepage loss control agent. These outcomes 
exhibited the possibility of applying FFWM as a substitutional for some of the toxic additives utilized in the drilling operations.

To sum it up, all these experimental investigations for various food waste products had the commonality that these friendly materials had the potential to be exploited as alternative or at least supportive additives for conventional nonbiodegradable chemical additives in terms of modifying the drilling fluid properties, and they will contribute to decreasing both the effect on the environment and personnel safety as well as minimizing the overall expenses of drilling mud and drilling waste handling. Table 3 is a summary of the results of PPP, MPP, GP, and FFWM compared with PTLP (Al-Hameedi et al. 2019b, c, d, e).

\section{Can PTLP additives substitute the conventional thinners used in water-based drilling fluid?}

Typically, the major function of the thinners that are used as traditional additives for different types of drilling mud is to improve the rheological properties by removing the clotting and flocculation in the drilling fluid. Thinners materials help to provide the desperation phenomenon in the mud instead of mud agglomeration. Additionally, some of the thinners additives can serve as fluid loss agents and $\mathrm{pH}$ reducers. It is crucial to point out that the most common thinners additives are lignosulphonate, chrome-lignite, and Resinex (Basra Oil Company 2008).

Starting with lignosulphonate material, it is a highly anionic polymer used to deflocculate clay-based muds. Lignosulfonate is a byproduct of the sulfite method for manufacturing paper from wood pulp. Lignosulfonate is a complex mixture of small- to moderate-sized polymeric compounds with sulfonate groups attached to the molecule. Chromium and iron compounds were admixed to get stability benefits at higher temperatures. The other minor function of the lignosulfonate additive is to improve the filtration characteristics and reduce $\mathrm{pH}$. Lignosulfonate is used to control rheology and provide filtration control through deflocculation of the bentonite. The field additive concentration is around $3-22 \mathrm{~kg} / \mathrm{m}^{3}(1-8 \mathrm{lb} / \mathrm{bbl})$. At temperatures greater than $325^{\circ} \mathrm{F}$, lignosulfonates degrade to form $\mathrm{CO}_{2}$ and carbonate ion. At temperatures greater than $403{ }^{\circ} \mathrm{F}$, lignosulfonates may degrade to liberate hydrogen sulfide and sulfide ion (Basra Oil Company 2016; Baker Hughes 2010; Schlumberger 2019).

Chrome-lignite is a lignite that has been treated with chromic or chromate salts, such as potassium or sodium chromate or dichromate or chromic chloride. It is an effective dispersant and fluid loss control agent in most waterbased muds. Chrome-lignite is an artificially altered lignite intended to be used as a drilling thinner, fluid stabilizer, and fluid loss decreasing operator in water-based muds. It is an efficient material for rheological properties, especially at high temperatures. Chrome-lignite is a lignite material that has been solubilized from caustic soda. It is highly soluble and exhibits stability at high temperatures. It is also more stable than lignite regarding temperature applications in clay-based water muds. The recommended treatment additive of chrome-lignite as a deflocculate material is $3-11 \mathrm{~kg} /$ $\mathrm{m}^{3}(1-4 \mathrm{lb} / \mathrm{bbls})$ and as a filtration control agent $5-22 \mathrm{~kg} /$ $\mathrm{m}^{3}$ (2-8 lb/bbls) (Basra Oil Company 2016; Baker Hughes 2010; Schlumberger 2019).

Resinex additive is a temperature-stable, synthetically formulated resin and lignite complex, which has been proven to be one of the most effective high-temperature thinners and filtration control-additives. Resinex is a broad fluid loss control additive that can be applied to any water-based mud. For field applications, Resinex obtained excellent results in freshwater, seawater, lime, lignosulfonate, polymer, and nondispersed systems. It also stabilizes and extends the temperature limitations and contamination resistance of water-based mud systems to above $200^{\circ} \mathrm{C}$. It is effective in high-density drilling fluids where fluid loss control can be achieved without an increase in viscosity. Normal treatment ranges from 6 to $17 \mathrm{~kg} / \mathrm{m}^{3}$ ( 2 to $6 \mathrm{lb} / \mathrm{bbls}$ ) depending on the desired viscosity, the degree of filtration control required, the original drilling fluid system characteristics, and the environment in which it is used (Basra Oil Company 2016; Baker Hughes 2010; Schlumberger 2019).
Table 3 Effect of variation in the concentration of various food waste products on properties of water-based mud

\begin{tabular}{|c|c|c|c|c|c|c|c|c|c|c|c|}
\hline \multirow[t]{2}{*}{ Property } & \multirow[t]{2}{*}{ RF } & \multicolumn{2}{|c|}{ PTLP } & \multicolumn{2}{|c|}{ PPP } & \multicolumn{2}{|c|}{ MPP } & \multicolumn{2}{|l|}{ GP } & \multicolumn{2}{|c|}{ FFWM } \\
\hline & & $11 \mathrm{~g}$ & $22 \mathrm{~g}$ & $6 \mathrm{~g}$ & $12 \mathrm{~g}$ & $6 \mathrm{~g}$ & $12 \mathrm{~g}$ & $7 \mathrm{~g}$ & $10.5 \mathrm{~g}$ & $10 \mathrm{~g}$ & $20 \mathrm{~g}$ \\
\hline PV (cp) & 8 & 9 & 13 & 7 & 8 & 14 & 24 & 9 & 13 & 8 & 9 \\
\hline YP $\left(\mathrm{lb} / 100 \mathrm{ft}^{2}\right)$ & 12 & 5 & 5 & 7 & 6 & 14 & 17 & 20 & 25 & 15 & 17 \\
\hline Initial gel strength $\left(\mathrm{Ib} / 100 \mathrm{ft}^{2}\right)$ & 15 & 6 & 7 & 9 & 8 & 10 & 10 & 22 & 26 & 17 & 18 \\
\hline Final gel strength $\left(\mathrm{Ib} / 100 \mathrm{ft}^{2}\right)$ & 20 & 11 & 12 & 13 & 12 & 14 & 14 & 26 & 33 & 25 & 27 \\
\hline Filtration $(\mathrm{cc} / 30 \mathrm{~min})$ & 12.5 & 9.25 & 8.5 & 11 & 10 & 7 & 6 & 7 & 6.25 & 8.5 & 7 \\
\hline Filter cake (mm) & 3 & 1.9 & 2 & 1.7 & 1.75 & 1.6 & 1.4 & 2 & 2.5 & 1.8 & 1.8 \\
\hline $\mathrm{pH}$ & 11 & 9.1 & 8.7 & 8.4 & 8.2 & 8 & 7.7 & 9.2 & 8.7 & 9.3 & 8.9 \\
\hline
\end{tabular}


The ultimate objective of this section is to show that PTLP waste products can be used as an alternative or supportive friendly additive for traditional non-biodegradable products such as lignosulphonate, chrome-lignite, and Resinex as it generated excellent results under the fresh and aged conditions. The laboratory outcomes showed the potential of PTLP to be used as flocculation and clotting reducer, $\mathrm{pH}$ reducer, and as a filtration control agent. In different words, PTLP additives have the potential to perform the same functions that conventional thinners additives can perform in the field. Thus, PTLP should be investigated more to be utilized in the field in order to guarantee its effectiveness in the drilling operations.

The popularity of using food waste products is mainly due to its cost and its friendly effect on the environment. Many investigations have been conducted regarding food waste products to test their effects on the drilling mud properties. In this experimental study, the laboratory results clarified that PTLP at low concentration $1.5 \%(11 \mathrm{~g})$ exhibited motivating results under the surface and sub-surface conditions, which in return suggest that this PTLP friendly additive compensates the thinners materials or at least reduce the consumption of them. However, to have a coherent image, a cohesive conclusion, and a rigorous answer, it is practically applicable to test the results in different temperatures and pressures using fresh and aged conditions to see if PTLP is applicable in the sub-surface conditions and hostile circumstances. Thus, more investigations should be carried out under downhole conditions as well as gathering the palm tree leaves instead of disposing of them.

\section{Conclusion}

Experimental investigations to understand the effects of PTLP and its validation in improving the performance of water-based mud have been conducted under the fresh and aged conditions, and the following conclusions were reached from the study:

- PTLP is a multifunctional bio-enhancer additive, with a significant increase in the YP and gel strength. However, PV was tangibly increased at 3\% concentration due to irregularity in particle size distribution and an inefficient crushing for palm tree leaves for the fresh conditions, while PV was negligibly influenced by $3 \%$ concentration for the aged conditions.

- PTLP showed a very good fluid loss control performance in water-based mud, as the addition of $1.5 \%$ and $3 \%$ concentrations of the additive for both fresh and aged environments resulted in reducing the fluid loss and provided a thin filter cake thickness as compared to the reference fluid.
- PTLP was found to decrease the $\mathrm{pH}$ of the reference fluid, suggesting its suitability to serve as a $\mathrm{pH}$ reducer for both fresh and aged situations.

- Due to the capability of PTLP to reduce YP, gel strength and the filtration volume, as well as improving the filter cake thickness, PTLP can be added to the drilling mud prior to securing the hole by the casing string.

- 3\% (22 g) concentration of the PTLP did not result in any remarkable improvement in YP and both the initial and final gel strengths. However, PV was majorly maximized at $3 \%$ concentration for the fresh conditions. Also, the filtration properties were slightly enhanced using 3\% (22 g) concentration, suggesting a lower concentration of $1-2 \%$ to be used of PTLP for optimal performance.

- The goal of this paper is to present new alternatives or supportive materials for drilling fluid additives, which is palm tree leaves (PTL). PTL are available everywhere and easily accessible in the Arabian Gulf countries such as Iraq, Saudi Arabia, and Kuwait as well as some parts of the USA. Thus, PTL are a very good candidate for further investigation. Additionally, the price for collecting and preparing PTL is much cheaper when comparing it with the conventional chemical additives.

- It is important to evolve environmentally friendly drilling mud additives such as PTLP to contribute in reducing the impact on the environment and the safety of personnel as well as the overall cost of drilling operations and drilling waste handling.

Open Access This article is distributed under the terms of the Creative Commons Attribution 4.0 International License (http://creativeco mmons.org/licenses/by/4.0/), which permits unrestricted use, distribution, and reproduction in any medium, provided you give appropriate credit to the original author(s) and the source, provide a link to the Creative Commons license, and indicate if changes were made.

\section{References}

Adebowale A, Raji J (2015) Local content supplements as an alternative to imported corrosion control additives for drilling mud treatment (A case study of the use of burnt plantain and banana peels. In: Proceedings of the international academic conference for sub-sahara african transformation and development, vol 3

Al-Hameedi AT, Alkinani HH, Dunn-Norman S, Flori RE, Hilgedick SA, Amer AS, Alsaba M (2018) Mud loss estimation using machine learning approach. J Pet Explor Prod Technol 9(2):13391354. https://doi.org/10.1007/s13202-018-0581-x

Al-Hameedi AT, Alkinani HH, Dunn-Norman S, Albazzaz HW, Alkhamis MM (2019a) Missouri University of Science and Technology. "Insights into eco-friendly and conventional drilling additives: applications, cost analysis, health, safety, and environmental considerations." Society of Petroleum Engineers, SPE symposium: Asia Pacific Health, Safety, Security, Environment and Social Responsibility held in Kuala Lumpur, Malaysia 
Al-Hameedi ATT, Alkinani HH, Dunn-Norman S, Al-Alwani MA, Alshammari AF, Alkhamis MM, Al-Bazzaz WH (2019b) Experimental investigation of environmentally friendly drilling fluid additives (mandarin peels powder) to substitute the conventional chemicals used in water-based drilling fluid. J Pet Exp Prod Technol. https://doi.org/10.1007/s13202-019-0725-7

Al-Hameedi AT, Alkinani HH, Dunn-Norman S, Alshammari AF, Albazzaz HW, Alkhamis MM, Mutar RA (2019b) Insights into the application of new eco-friendly drilling fluid additive to improve the fluid properties in water-based drilling fluid systems. J Pet Sci Eng (accepted)

Al-Hameedi AT, Alkinani HH, Dunn-Norman S, Alashwak NA, Alshammari AF, Alkhamis MM, Albazzaz HW (2019c) Missouri University of Science and Technology; Mutar, R.A., Ministry of Communications and Technology; Alsaba, M.T., Australian College of Kuwait. "Environmentally friendly drilling fluid additives: Can food waste products be used as thinners and fluid loss control agents for drilling fluid?" Society of Petroleum Engineers, SPE symposium: Asia Pacific Health, Safety, Security, Environment and Social Responsibility held in Kuala Lumpur, Malaysia

Al-Hameedi ATT, Alkinani HH, Dunn-Norman S, Alashwak NA, Alshammari AF, Alkhamis MM, Ashammarey A (2019e) Evaluation of environmentally friendly drilling fluid additives in water-based drilling mud. Soc Pet Eng. https://doi.org/10.2118/195510-ms

Ali MS, Al-Marhoun MA (1990) The effect of high temp., high pressure and aging on water-base drilling fluids. Society of petroleum engineers

Alkinani HH, Al-Hameedi AT, Dunn-Norman S, Flori RE, Alsaba MT, Amer AS, Hilgedick SA (2019) Using data mining to stop or mitigate lost circulation. J Pet Sci Eng 173:1097-1108. https:// doi.org/10.1016/j.petrol.2018.10.078

Amadi K, Alsaba M, Iyalla I, Al Dushaishi Al-Hameedi AT, Alkinani HH (2018) Empirical studies of the effectiveness of bio-enhancers (food waste products) as suitable additives in environmental friendly drilling fluid systems. Paper AADE-18-FTCE-105, presented at the 2018 AADE fluids technical conference and exhibition held at the Hilton Houston North Hotel, Houston

Amanullah M (2007) Screening and evaluation of some environmentfriendly mud additives to use in water-based drilling muds. In: SPE E\&P environmental and safety conference, Galveston
Baker Hughes (2010) Specialty products: drilling fluids solution. http:// www.bakerhughes.com/news-and-media/resources/brochures/ specialty-products-brochure. Accessed 27 Feb 2019

Basra Oil Company. Various daily reports, final reports, and tests for 2006, 2007, 2008, 2009 and 2010, 2011, 2012, 2013, 2016. Several drilled wells, Basra oil Fields, Iraq

Chesser BG, Enright DP (2013) High-temperature stabilization of drilling fluids with a low-molecular-weight copolymer. J Pet Technol 32(6):950-956. https://doi.org/10.2118/8224-PA

Fann Instrument Company (2005) Aging of water based drilling fluids. https://www.fann.com/fann/default.html. Accessed 24 Apr 2019

Iheagwara $\mathrm{O}$ (2015) Comparative analysis of the use of banana peels and $\mathrm{NaOH}$ in $\mathrm{Ph}$ control in Nigerian clays. J Niger Assoc Math Phys 30:197-202

Iranwan S, Azmi A, Saaid M (2009) Corn cobs and sugar cane waste as viscosifier in drilling fluid. Pertan J Sci Technol 17:173-181

Nmegbu J, Bekee BA (2014) Evaluation of corn cob cellulose and its suitability for drilling mud formulation. J Eng Res Appl 4:112-117

Nyeche W, Nmegbu J, Ifeoma P (2015) Drilling mud formulation using potato starch (Ipomoea Batatas). J Eng Res Appl 5:48-54

Okon AN, Udoh FD, Bassey PG (2014) Evaluation of rice husk as fluid loss control additive in water-based drilling mud. Soc Pet Eng. https://doi.org/10.2118/172379-ms

Okorie MO (2009) Modification of drilling fluid PH with local additives (Ash of burnt palm head sponge [BPHSP] and a rich potash mineral known as Trona. Pet Technol Dev J 1:1-16

Omotioma M, Ejikeme PCN, Mbah GO (2014) Comparative analysis of the effects of cashew and mango extracts on the rheological properties of water based mud. J Eng Res Appl 4:56-61

Schlumberger Company, Oilfield Glossary. https://www.glossary.oilfi eld.slb.com/en/Terms/1/lignosulfonate.aspx. Accessed $27 \mathrm{Feb}$ 2019

Zafar S (2016) Biomass potential of date palm wastes. Agriculture, Biomass Energy, Middle East, Renewable Energy, Waste Management. https://www.ecomena.org/biomass-date-palm-wastes/. Accessed Apr 2019 